\title{
Kontekstualisme pada Pusat Pelatihan Search and Rescue
}

\author{
Dinda Miftakhul Roisyah dan Hari Purnomo \\ Departemen Arsitektur, Fakultas Teknik Sipil dan Perencanaan, Institut Teknologi Sepuluh Nopember (ITS) \\ e-mail: hari_poeng19@yahoo.com
}

\begin{abstract}
Abstrak-Bencana tidak dapat dihindari. Hal ini tentunya menjadi salah satu isu penting di setiap negara, termasuk Indonesia. Selain itu, bencana tidak lepas dari kerugian -semakin cepat ditangani akan semakin kecil kerugian yang ditimbulkan. Maka dari itu tindakan penanggulangan bencana memegang peranan kunci dalam menghadapi bencana. Badan SAR Nasional (BASARNAS) merupakan tim yang berperan atau bertugas dalam menangani kasus sehubungan bencana, musibah, kecelakaan, dan lainnya. Penanganan ini tentunya membutuhkan skill tertentu yang didapatkan dari serangkaian pelatihan terkait. Fasilitas wadah pelatihan ini diharapkan mampu memberikan fungsi terbaik, yakni dengan merancang sesuai dengan konteks, dalam hal ini fenomena alam dan lingkungan sekitar. Sehingga fasilitas ini menghadirkan suasana yang menyerupai kondisi alam yang menjadi fokusan dari pelatihan.
\end{abstract}

Kata Kunci-Anak Jalanan, Arsitektur Perilaku, Fleksibilitas Arsitektur.

\section{PENDAHULUAN}

$\mathrm{U}$ NDANG-UNDANG No. 29 tahun 2014 tentang Pencarian dan Pertolongan menegaskan bahwa pemerintah membentuk Badan Nasional Pencarian dan Pertolongan (sekarang BASARNAS) untuk menyelenggarakan urusan pemerintahan di bidang Pencarian dan Pertolongan. Penyelenggaraan operasi Pencarian dan Pertolongan bertujuan di antaranya untuk melakukan pencarian serta memberikan pertolongan, penyelamatan, dan evakuasi korban secara cepat, tepat, aman, terpadu dan terkoordinasi; dan juga mencegah dan mengurangi kefatalan dalam kecelakaan [1].

Melaksanakan pembinaan kemampuan dan kesiapan sumberdaya manusia serta koordinasi berkelanjutan agar setiap saat dapat melaksanakan tugas operasi pencarian dan pertolongan dengan sebaik-baiknya merupakan salah satu misi dari BASARNAS [2]. Pembinaan ini diberikan dalam bentuk pelatihan-pelatihan terkait pencarian dan pertolongan dalam upaya penanganan bencana (Gambar 1). Dan pelatihan ini pada umumnya diselenggarakan di markas militer di sebuah kawasan tertentu dan selebihnya diberikan di kantor pusat/ kantor cabang dari BASARNAS dan badan-badan pemerintahan terkait. Belum ada satu fasilitas tertentu yang menghadirkan hampir keseluruhan sarana pelatihan pencarian dan pertolongan terkait penanggulangan bencana. Hal ini bisa menjadi salah satu kekurangan dalam penangangan bencana di Indonesia.

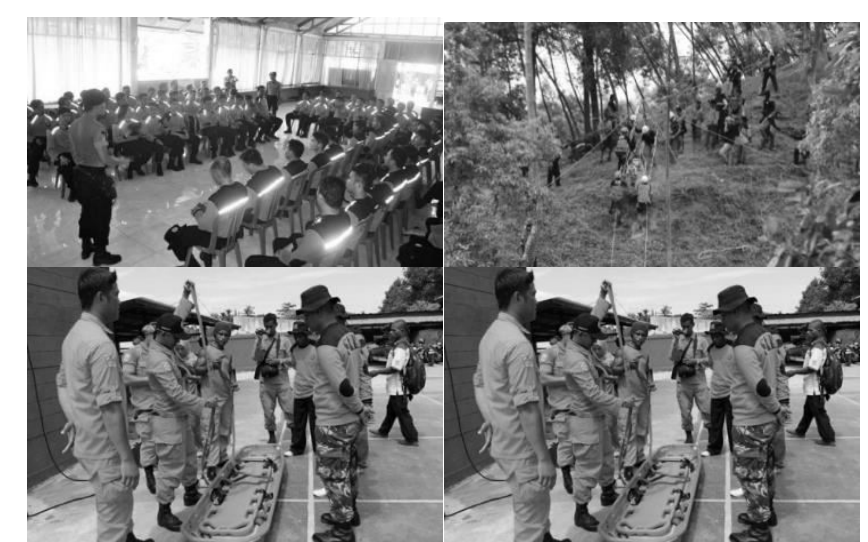

Gambar 1. Pelatihan kemampuan dan kesiapan oleh BASARNAS. (Sumber: basarnas.go.id)

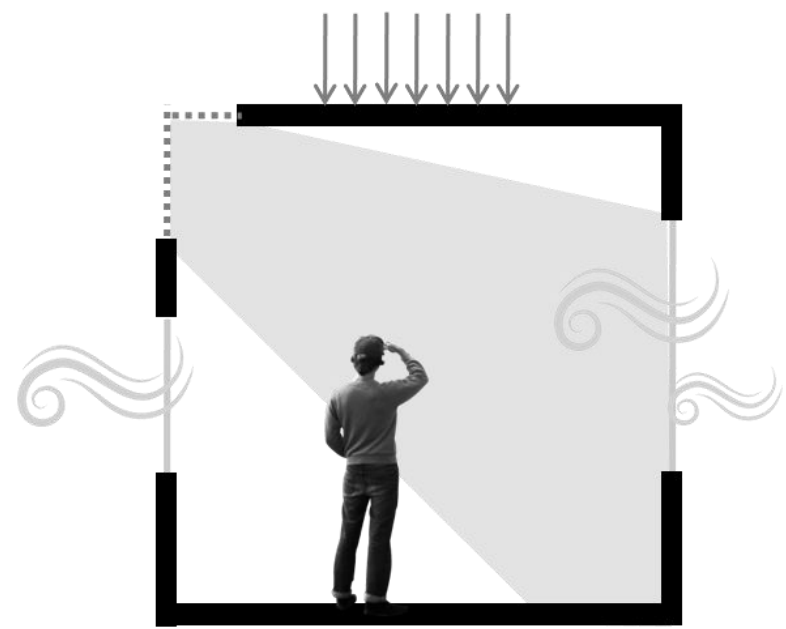

Gambar 2. Ilustrasi konsep fasilitas.

(Sumber: Dok. pribadi)

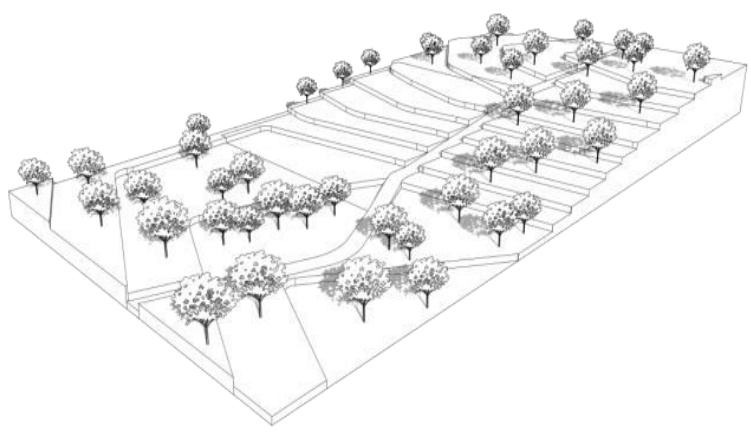

Gambar 3. Ilustrasi kontur tapak.

(Sumber: Dok. pribadi) 


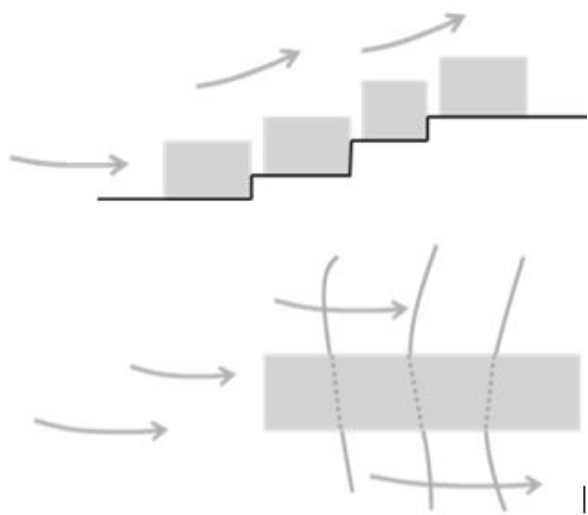

Gambar 4. Ilustrasi konsep bangunan terhadap kontur. (Sumber: Dok. pribadi)

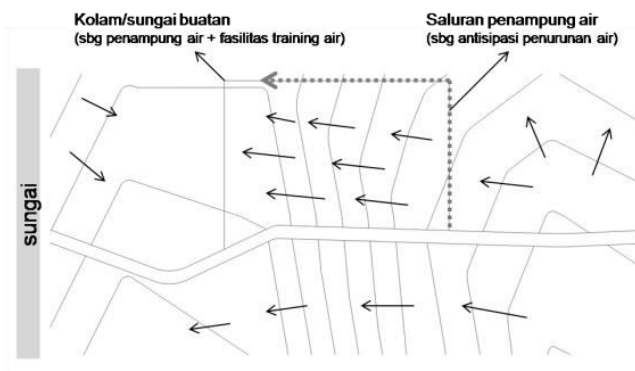

Gambar 6. Ilustrasi eksisting air dan saluran khusus.

(Sumber: Dok. pribadi)

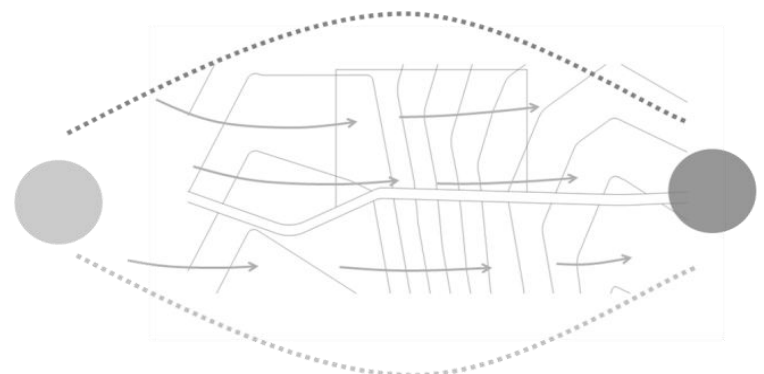

Gambar 7. Ilustrasi sinar matahari dan orientasi bangunan.

(Sumber: Dok. pribadi)

Dilihat dari permasalahan di atas maka dibutuhkan sebuah fasilitas dengan fungsi utama mewadahi kegiatan pelatihanpelatihan pencarian dan pertolongan terkait penanggulangan bencana yang mampu menghadirkan hampir keseluruhan fungsi fasilitas yang dibutuhkan sesuai jenis bencana dan kecelakaan yang terjadi di Indonesia dengan memanfaatkan dengan maksimal kondisi eksisting sekitar sebagai bentuk respon dan wujud dari alam itu sendiri yang juga mampu membantu menguatkan image BASARNAS sekaligus meningkatkan kesadaran masyarakat terkait bencana.

\section{METODE}

Metode yang digunakan dalam merancang fasilitas ini yakni dengan metode kontekstual (contextualism). Ada beberapa pendapat mengenai kontekstualisme ini, misalnya O.M. Ungers yang menyatakan bahwa kontekstualisme yakni dimana beliau menggambarkan diagram abstrak mengenai

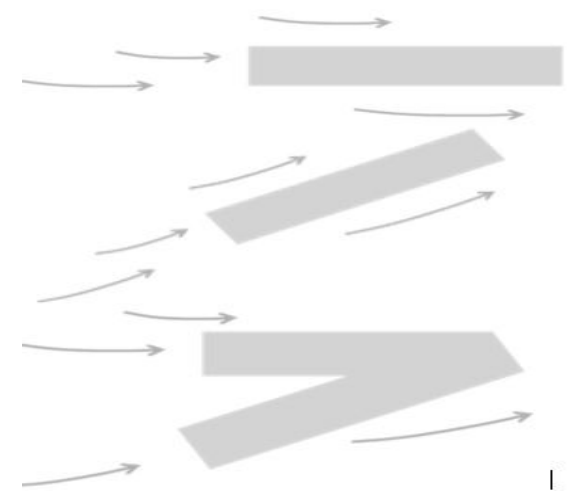

Gambar 8. Ilustrasi sinar matahari dan orientasi bangunan. (Sumber: Dok. pribadi)

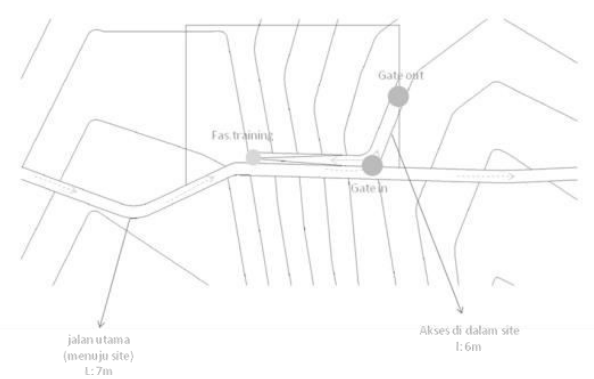

Gambar 9. Ilustrasi akses utama dan tambahan (Sumber: Dok. pribadi)

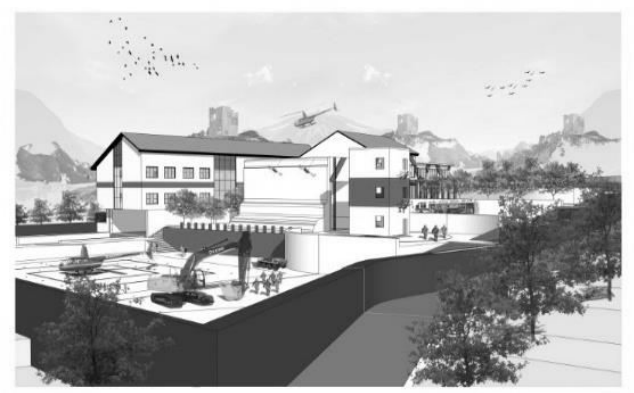

Gambar 10. Perspektif

(Sumber: Dok. pribadi)

morfologi dari sebuah lingkungan (mulai dari sudut atap, sumbu jendela, tekstur dan sebagainya) kemudian berusaha untuk menyusunnya kembali ke dalam komposisi yang baru dengan karakteristik yang sama [3].

Sedangkan dari pengertiannya sendiri kontekstualisme (contextualism) atau juga dikenal dengan arsitektur kontekstual (contextual architecture) yakni sebuah arsitektur dimana arsitektur ini merespon lingkungan sekitarnya dengan menghargai apa yang sudah ada di sana (eksisting) [4].

Metode ini dipilih dengan tujuan mampu merespon alam/ lingkungan sekitar hingga menghadirkan fasilitas pelatihan yang menyerupai alam itu sendiri. Dalam hal ini kontekstualisme dihadirkan melalui dampak lingkungan sekitar terhadap bangunan itu sendiri (environment impact to the site) dan menjadi isu desain sesuai metode desain milik Duerk [5]. 


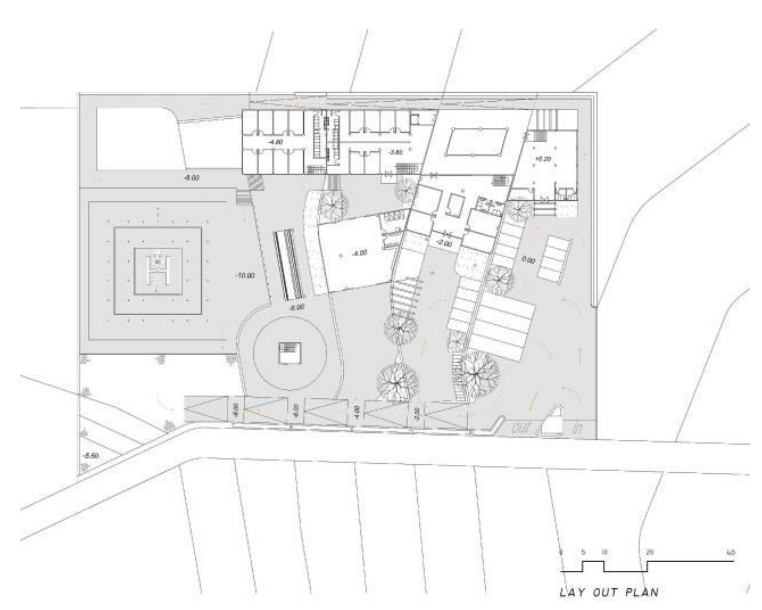

Gambar 11. Alur jogging track mengelilingi fasilitas (Sumber: Dok. pribadi)

Dengan pendekatan bangunan tropis yang disesuaikan dengan konteks lingkungan objek, maka perlu diperhatikan beberapa faktor penting terkait bangunan tropis, faktor ini antara lain: orientasi bangunan, vegetasi yang berada disekitar bangunan, cahaya matahari yang mengenai bangunan, arah angin, suhu dan kelembaban udara, aktivitas di dalam bangunan dan sekitar bangunan, dan penghawaan dalam ruangan [6]. Faktor-faktor ini yang akan menjadi panduan dalam merancang fasilitas pelatihan yang mampu merespon alam sekitar.

\section{HASIL EKSPLORASI}

\section{A. Konsep Desain}

Fasilitas training dihadirkan dengan menonjolkan alam sebagai bagian dari bangunan itu sendiri sehingga user dalam hal ini peserta pelatihan akan semakin tajam dalam merasakan lingkungan dan juga pastinya terbiasa dengan kondisi alam yang tidak bisa ditebak dan tidak selalu mulus (Gambar 2).

Namun sebelum itu perlu adanya analisa terhadap lingkungan sekitar yang kemudian dilibatkan ke dalam elemen rancang fasilitas pelatihan ini seperti yang dijelaskan sebelumnya.

- $\quad$ KONTUR. Intervensi terhadap kontur eksisting (Gambar 3 dan 4) diminimalkan dengan pertimbangan kontur digunakan sebagai bagian dari zonasi fungsi bangunan dalam fasilitas itu sendiri (Gambar 5).

- AIR. Dengan adanya kolam penampung buatan pada bagian terendah kontur dalam lahan, akan membantu mengatasi masalah lahan terkait penurunan air. Kolam buatan ini dapat digunakan sebagai fasilitas water training (Gambar 6).

- Sinar Matahari dan Orientasi Bangunan. Orientasi bangunan dibuat sejajar dengan bangunan, akan tetapi bukaannya mengindari berkas matahari terbit dan tenggelam (barat dan timur) untuk mengurangi panas dalam bangunan, dikarenakan bangunan didesain menggunakan pendingin alami (tidak menggunakan AC), sehingga diperlukan untuk menghindari kemungkinan

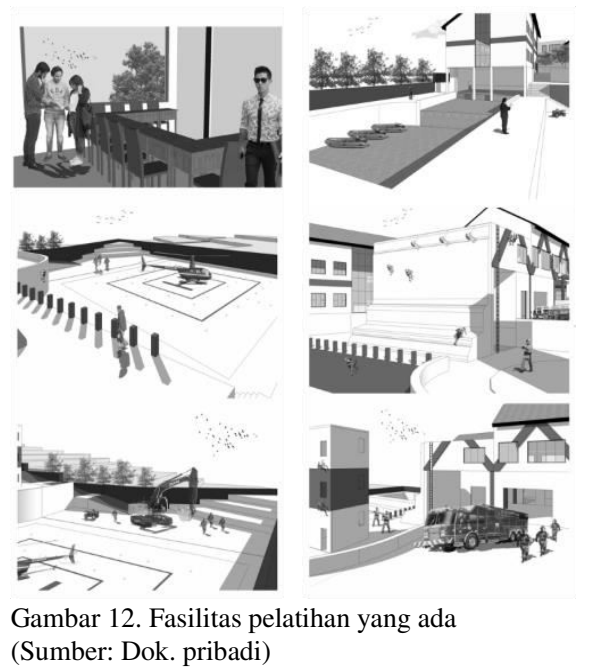

panas yang berlebih (Gambar 7 dan 8).

- AKSES. Diberikan akses khusus menuju area training outdoor dengan pertimbangan alat berat dan kendaraan bermassa besar yang digunakan dalam proses training (Gambar 9).

\section{B. Aspek Formal - Bentuk}

Sesuai dengan metode yang digunakan yang kontekstualisme maka aspek formal bangunan berkonsep merespon alam, sehingga fenomena-fenomena alamlah yang menjadi orientasi bentukan, warna, kesan ruang yang diciptakan, dan sebagainya (Gambar 10).

Bentukan bangunan utama berorientasi searah dengan arah matahari, namun bukaan pada bangunan menghindari arah matahari dengan tujuan mengurangi beban panas dan berkas cahaya berlebih. Atap pelana merespon iklim tropis eksisting terkait curah hujan. Intervensi terhadap kontur eksisting diminimalkan dengan pertimbangan kontur digunakan sebagai bagian dari zonasi fungsi bangunan dalam fasilitas itu sendiri, semakin ke bawah semakin privat zona dan fungsi dari bangunan (zona publik - semi publik - privat).

\section{Aspek Formal - Fasilitas Pelatihan}

Fasilitas pelatihan indoor berupa ruang-ruang kelas yang dibedakan berdasarkan jenis simulasi dan pendidikan yang diberikan, terdapat pula ruang komputasi dan ruang simulasi yang membantu peserta pelatihan membayangkan situasi dan berpikir apa yang selanjutnya harus dilakukan. Ada pula ruang auditorium yang mampu menampung seluruh peserta sekaligus, digunakan untuk menyampaikan kuliah seputar bencana dan penanganan/ penanggulangannya. Dilengkapi dengan asrama yang menjadi tempat beristirahat peserta pasca pelatihan berlangsung.

Fasilitas pelatihan outdoor terdiri dari water training, vertical rescue, fire fighter, hellipad, dan heavy machine area. Dilengkapi dengan garasi kendaraan berat yang digunakan dalam pelatihan (mobil pemadam, excavator, mobil amfibi, dan sebagainya) serta alur jogging track untuk melatih peserta dalam menghadapi medan yang tidak mudah dan beragam (Gambar 11 dan 12). 


\section{KESIMPULAN/RINGKASAN}

Terkait permasalahan bencana dan penanggulangannya dan juga BASARNAS dibutuhkan sebuah fasilitas pelatihan yang berfungsi memberikan pembekalan berbentuk pendidikan, pelatihan, dan termasuk interaksi sosial. Alam sebagai faktor penting dari bencana menjadi patokan dalam merancang sebuah fasilitas pelatihan terkait pencarian dan pertolongan penanggulangan bencana dan dengan metode kontekstualisme yang digunakan agar fasilitas ini mampu merespon alam sekitarnya sehingga meningkatkan ketanggapan peserta pelatihan dalam melakukan operasi pencarian dan pertolongan terkait penanggulangan bencana.
Hal ini ditujukan untuk menekan kerugian berupa nyawa/jiwa dan juga materi yang diakibatkan bencana yang tidak dapat dihindari, namun dapat ditanggulangi.

\section{DAFTAR PUSTAKA}

[1] Sekertariat Kabinet Republik Indonesia, "UU No.29 Tahun 2014," 2014.

[2] Basarnas, "Official Website Badan SAR Nasional."

[3] J. Kari, Basic Design Methods. Swiss: Birkhäuser, 2008.

[4] Encyclopedia.com, "Contextual architecture (contextualism)." [Online]. Available: http://encyclopedia.com/education/dictionariesthesauruses-pictures-and-press-release/contextual-architexture.

[5] D. Duerk, Architectural Programming: Information Management for Design. New York: Van Nostrand Reinhold Company, 1993.

[6] G. Brown, Sun, Wind, and Light Architectural Design Strategies. John Wiley \& Sons, 1985. 